\title{
Fat intake and breast milk fatty acid composition in farming and nonfarming women and allergy development in the offspring
}

\author{
Karin Jonsson', Malin Barman', Sara Moberg' ', Agneta Sjöberg' ${ }^{2}$, Hilde K. Brekke, Bill Hesselmar', Susanne Johansen ${ }^{5}$, \\ Agnes E. Wold ${ }^{6}$ and Ann-Sofie Sandberg ${ }^{1}$
}

BACKGROUND: Children growing up on small family farms are at much lower risk of developing allergy than other children. We hypothesized that low intake of margarine and polyunsaturated fats among farming families could contribute to this protection.

METHODS: Twenty-eight mother-infant pairs living on small dairy farms and 37 nonfarm rural resident pairs were recruited in the FARMFLORA birth cohort. Food items expected to affect dietary fat composition were recorded by food frequency questionnaires during pregnancy and by 24-h recalls followed by $24-h$ food diaries during lactation. Allergy was diagnosed by doctors, using strict predefined criteria. Maternal diet and breast milk fat composition were compared between farming and nonfarming mothers and related to children's allergy at age $3 y$.

RESULTS: Farming mothers consumed more butter, whole milk, saturated fat, and total fat than nonfarming mothers, who consumed more margarine, oils, and low-fat milk. Farming mothers' breast milk contained higher proportions of saturated and lower proportions of polyunsaturated fat. Allergy was eight times more common in nonfarm children. Mothers of allergic children consumed more margarine and oils than mothers of nonallergic children.

CONCLUSION: Low maternal consumption of margarine and vegetable oils might contribute to the allergy-preventive effect of growing up on small dairy farms.

$\mathbf{T}^{\mathrm{T}}$ he prevalence of allergy rose dramatically during the 20th century in Western countries. In Sweden, allergies affect almost every third child, thereby being the most common chronic disease in the young (1). The etiology of allergy is multifactorial and the underlying factors of the rise in allergies are not yet established. Farmers' children have markedly low incidence of allergy (2-5). Protective factors such as regular contact with livestock (4-6) and intake of unpasteurized farm milk $(6,7)$ have been identified but cannot fully explain the low allergy prevalence in farmers.

Farm children have been found to have a higher butter and whole milk intake, as well as a lower intake of margarine and low-fat milk, compared with nonfarm children (8). Consumption of margarine and vegetable oils has increased in parallel with the rise in allergies, as observed by Black and Sharpe in 1997 (9). They proposed that a high intake of margarine and accompanying omega- 6 polyunsaturated fatty acids (PUFAs) was underlying the rise in allergy prevalence (9). Later, Sausenthaler et al. identified margarine as a risk factor for developing allergic diseases in a systematic review of fat intake and allergy (10).

We hypothesized that higher intakes of dairy products and saturated fats and lower intakes of margarines, vegetable oils, and omega-6 (n-6) PUFAs in farmers compared with nonfarmers may contribute to the lower prevalence of allergy in farm children. The FARMFLORA birth cohort was established to investigate lifestyle factors of a farming environment in relation to allergy-related parameters. Mother-children pairs, who lived either on small dairy farms or in the same rural area but not on farms, were studied. To investigate the very early effect of dietary exposure on allergy development in the present study, diet during pregnancy and lactation as well as breast milk fatty acid composition were compared between farming and nonfarming mothers and related to allergy in the children at $3 \mathrm{y}$ of age.

\section{RESULTS}

Characteristics of farm and nonfarm children are displayed in Table 1, alongside characteristics of healthy and allergic nonfarm children. In the farming group, paternal allergic heredity and allergy prevalence was markedly lower compared with the nonfarming group ( 4 vs. $32 \%, P=0.004$ ); also paternal

\footnotetext{
'Division of Food and Nutrition Science, Department of Biology and Biological Engineering, Chalmers University of Technology, Gothenburg, Sweden; ${ }^{2}$ Department of Food and Nutrition, and Sport Science, University of Gothenburg, Gothenburg, Sweden; ${ }^{3}$ Department of Internal Medicine and Clinical Nutrition, University of Gothenburg, Gothenburg, Sweden; ${ }^{4}$ Department of Paediatrics, Institute of Clinical Sciences, University of Gothenburg, Gothenburg, Sweden; ${ }^{5}$ Pediatric Clinic, Skaraborg Hospital, Lidköping, Sweden; ${ }^{6}$ Clinical Bacteriology, Department of Infectious Diseases, Institute of Biomedicine, University of Gothenburg, Gothenburg, Sweden. Correspondence: Karin Jonsson (karin.jonsson@chalmers.se)

Received 14 April 2015; accepted 15 July 2015; advance online publication 21 October 2015. doi:10.1038/pr.2015.187
} 
Table 1. Characteristics of farm and nonfarm children and healthy and allergic nonfarm children in the FARMFLORA birth cohort

\begin{tabular}{|c|c|c|c|c|c|c|}
\hline \multirow[b]{2}{*}{ Variable } & \multirow[b]{2}{*}{ Farmers $(n=28)$} & \multirow[b]{2}{*}{ Nonfarmers $(n=37)$} & \multirow[b]{2}{*}{$P^{b}$} & \multicolumn{3}{|c|}{ Nonfarmers ${ }^{a}$} \\
\hline & & & & Healthy $(n=21)$ & Allergic $(n=10)$ & $p^{b}$ \\
\hline \multicolumn{7}{|l|}{ Antenatal characteristics } \\
\hline Mothers & $7(25 \%)$ & $11(30 \%)$ & 0.67 & $4(19 \%)$ & $5(50 \%)$ & 0.11 \\
\hline Fathers & $1(4 \%)$ & $12(32 \%)$ & 0.004 & $6(29 \%)$ & $3(30 \%)$ & 1.0 \\
\hline \multicolumn{7}{|l|}{ Education level $(1=\text { lowest, } 5=\text { highest })^{\mathrm{e}}$} \\
\hline Mothers & $2(1-5)$ & $4(1-5)$ & $0.20^{\mathrm{d}}$ & $5(1-5)$ & $4(2-5)$ & $0.78^{\mathrm{C}}$ \\
\hline Fathers & $2^{f}(1-5)$ & $2^{f}(1-5)$ & $0.02^{d}$ & $2(1-5)$ & $3(2-4)$ & $0.89^{\circ}$ \\
\hline \multicolumn{7}{|l|}{ Smoking during last month of pregnancy } \\
\hline Mothers & $0(0 \%)$ & $1(3 \%)$ & 0.38 & $1(5 \%)$ & $0(0 \%)$ & 1.0 \\
\hline \multicolumn{7}{|l|}{ Birth characteristics } \\
\hline Gestational week ${ }^{g}$ & $40(37-42)$ & $39(36-42)$ & $0.13^{d}$ & $39(36-42)$ & $38(36-41)$ & $0.18^{\mathrm{c}}$ \\
\hline Cesarean section & $3(12)$ & $7(19 \%)$ & 0.36 & $3(14 \%)$ & $4(40 \%)$ & 0.17 \\
\hline Birth weight ${ }^{\mathrm{h}}(\mathrm{g})$ & $3,495(2,780-4,740)$ & $3,618(2,440-4,830)$ & $0.78^{d}$ & $3,655(2,440-4,435)$ & $3,205(2,730-4,830)$ & $0.25^{\circ}$ \\
\hline \multicolumn{7}{|l|}{ Infant characteristics } \\
\hline Male gender & $10(37 \%)$ & $23(62 \%)$ & 0.04 & $13(62 \%)$ & $9(90 \%)$ & 0.21 \\
\hline Exclusively breastfed (mo) & $4.0(0.0-6.0)$ & $3.5(0.0-6.0)$ & $0.11^{d}$ & $4.0(0.0-5.0)$ & $0.5(0.0-4.0)$ & $0.02^{\circ}$ \\
\hline Partially breastfed (mo) & $7.8(5.0-11)$ & $8.0(4.0-12)$ & $0.74^{d}$ & $8.5(4.0-12)$ & $5.0(2.5-7.0)$ & $0.04^{\circ}$ \\
\hline
\end{tabular}

Data are presented as $n$ (\%) or median (range).

aSix subjects excluded: 1 changed residence and 5 were allergic at 1.5 y but not $3 \mathrm{y} .{ }^{b} \chi^{2}$ test. ${ }^{~}$ Doctor's diagnosed asthma, rhinitis, or atopic eczema. ${ }^{\mathrm{d}} \mathrm{Mann}-\mathrm{Whitney} U$-test. ${ }^{\mathrm{e}} 1=$ elementary school, 2 = upper secondary school $2-3$ y or equivalent, $3=$ qualified graduate from upper secondary engineering course, $4=$ university $\leq 1$, and $5=$ university $>$ $1 \mathrm{y}$. ${ }^{\mathrm{M}}$ Mean: farmers $=2$, nonfarmers $=3 .{ }^{9}$ For farmers and nonfarmers, $n=27$ and 36 , respectively. ${ }^{\mathrm{h}}$ For nonfarmers, $n=36$. 'Doctor's diagnosis of asthma, atopic eczema, allergic rhinoconjunctivitis, or food allergy.

educational level and proportion of male gender were lower (Table 1). Paternal heredity did not differ between healthy and allergic subject ( 29 vs. $30 \%, P=1.0$ ), nor did any other variable except for duration of exclusive and partial breast-feeding (Table 1). Two farming mothers with nonallergic children reported intake of fish oil supplements during lactation.

\section{Diet in Farming and Nonfarming Mothers}

To examine dietary differences between farming and nonfarming mothers, a multivariate regression model using Orthogonal Projections to Latent Structures - Discriminant Analysis (OPLS-DA), was used. The final model $\left(R^{2}=0.28\right.$ and $Q^{2}=0.39$ ), including variables with the strongest discriminatory power (Variable Influence on Projection (VIP) $\geq 1.0$ ), contained only one (predictive) latent variable. Beside the multivariate OPLS-DA, univariable analyses (Mann-Whitney $U$-test) were performed on all variables to obtain $P$ values. Information about differences that were found to be significant in univariable analysis were added in retrospect to the figures of the multivariate models. In Figure 1, the OPLS-DA loading column plot shows that farming mothers consumed more butter during pregnancy $(P=0.02)$, while nonfarming mothers consumed more margarine $(P=0.001)$, margarine and oils in total $(P<0.001)$, and low-fat milk $(P=0.009)$; actual intakes are shown in Table 2. Similar findings were made during lactation; farming mothers consumed more full-fat milk $(P=0.02)$ and saturated fatty acids $(P=0.03)$ than nonfarming mothers (Figure 1, Table 2). A larger percentage of the energy was derived from saturated fat $(P=0.003)$ and fat in total $(P$ $=0.03$ ) in farming than nonfarming mothers (Figure 1, Table 2). Nonfarming women also consumed more margarine and margarine plus oil during lactation, according to the OPLS-DA model (Figure 1), although the difference did not reach significance in the Mann-Whitney $U$-test $(P=0.14$ and 0.20 , respectively; Table 2).

\section{Fatty Acids in Breast Milk in Farming and Nonfarming Women}

Breast milk collected at 4 mo postpartum was analyzed regarding the proportion of a range of saturated and unsaturated fatty acids (Figure 1). The breast milk of farming mothers contained higher proportions of saturated fatty acids compared to nonfarming mothers' milk (8.6 vs. $7.3 \%$, 


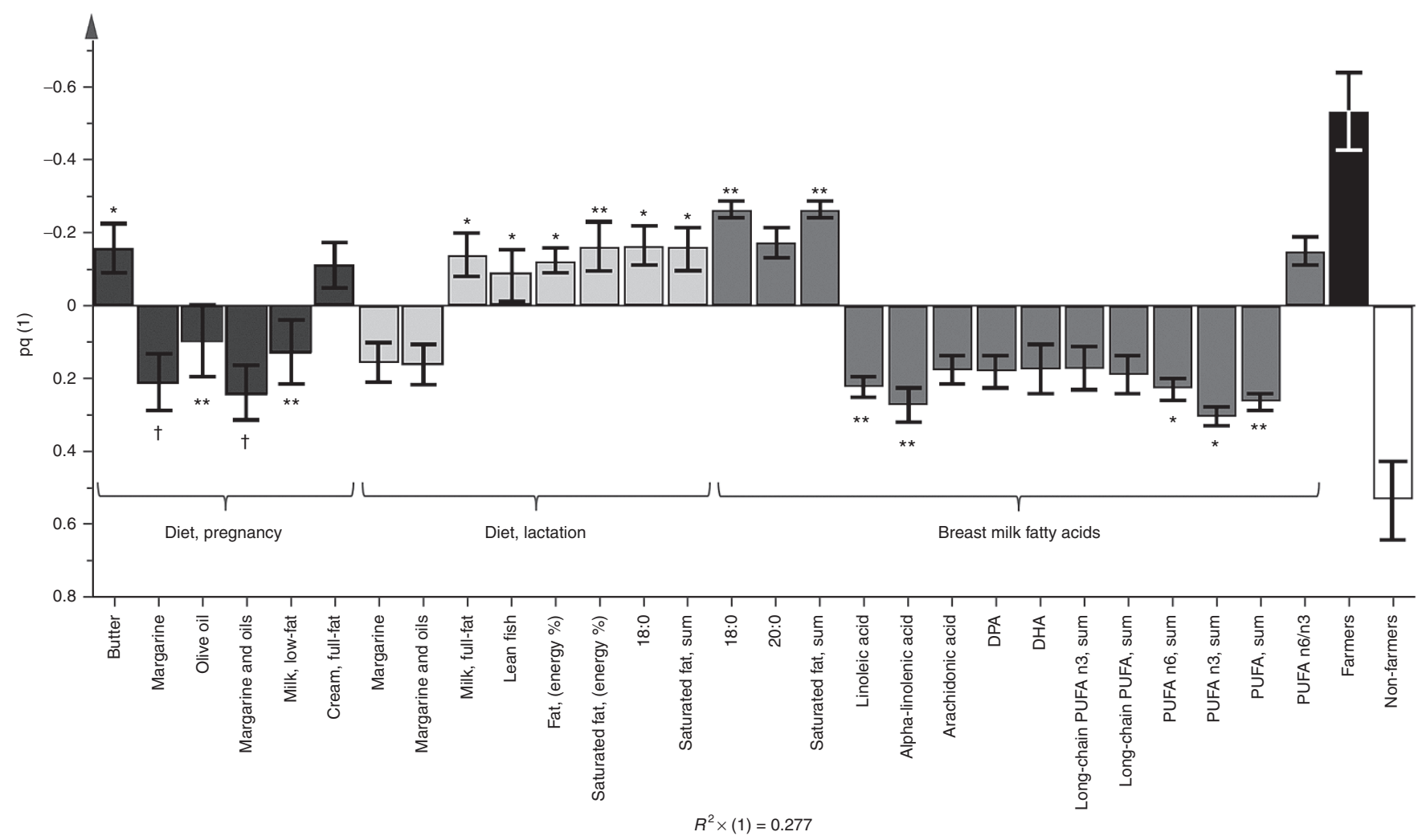

Figure 1. Diet and breast milk fatty acid composition in farming and nonfarming mothers. The one-dimensional Orthogonal Projections to Latent Structures with Discriminant Analysis (OPLS-DA) column loading plot displays differences in dietary fatty food intake and breast milk fatty acid composition between farming and nonfarming mothers. Variables with highest discriminatory power (Variable Influence on Projection (VIP) $\geq 1.0)$ are displayed, others were eliminated from the model. Variables pointing in the same direction as the "farmer" column are higher in the farming group, while those pointing in the opposite direction are highest in the nonfarming group. The higher the column, the greater the contribution of the variable to the model; error bars denote the $95 \%$ confidence level. One component is included in this model; $R^{2}=0.28$ and $Q^{2}=0.39$. Information about univariable significances have been added to the figure in retrospect, analyzed by univariable Mann-Whitney $U$-test $\left({ }^{*} P \leq 0.05,{ }^{* *} P \leq 0.01,{ }^{\dagger} P \leq 0.001\right) . n$ (dietary data, pregnancy) $=21$ for farmers and 36 for nonfarmers; $n$ (dietary data, lactation) $=19$ for farmers and 25 for nonfarmers; $n$ (breast milk data) $=15$ for farmers and 19 for nonfarmers. DHA, docosahexaenoic acid; DPA, docosapentaenoic acid; PUFA, polyunsaturated fatty acid. Explanations: Butter, includes butter-based margarines; Cream, includes crème fraîche and similar fatty dairy products; Milk, includes sour milk and yoghurt; Sum, the sum of all fatty acids analyzed.

$P=0.005)$, which instead contained significantly higher proportions of linoleic acid $(n-6 ; 10.9$ vs. $9.0 \%, P=0.01)$ and alpha-linolenic acid ( $n-3 ; 1.4$ vs. $1.1 \%, P=0.01)$ than that of farming mothers.

\section{Diet and Breast Milk Fatty Acid Pattern in Mothers of Healthy and Allergic Children}

One of 28 (4\%) farm children and 10 of 37 (32\%) nonfarm children developed allergy at $3 \mathrm{y}$ of age (Table 1), which has previously been reported (11). We compared the diet during pregnancy of mothers of allergic and healthy children, as well as breast milk fatty acid composition. Any allergy was used as outcome, due to the small sample size of the study. The final OPLS-DA model included one component (VIP $\geq$ $1.0, R^{2}=0.24$ and $Q^{2}=0.39$; Figure 2). Mothers of allergic children consumed more margarine, margarine plus oils, and low-fat milk during pregnancy $(P=0.01,0.003$, and 0.02 , respectively) as well as more margarine and margarine plus oils during lactation ( $P=0.02$ and 0.03 , respectively), compared with mothers of healthy children (Figure 2, Tables 3 and 4). Breast milk of mothers of allergic children contained higher proportions of the monounsaturated fatty acid 18:1 $n-9$ (39.1 vs. $36.4 \%, P=0.04$ ) than that of mothers of healthy children, which instead contained higher proportions of the saturated fatty acid 18:0 (7.8 vs. $6.8 \%, P=0.04)$ and the longchain omega-3 PUFA docosahexaenoic acid (DHA; 0.2 vs. $0.1 \%, P=0.03$; Figure 2). Mothers of healthy children also had a lower arachidonic acid to DHA ratio (1.5 vs. 2.0, $P=$ 0.03; Figure 2).

As allergic children were almost exclusively found in the nonfarming group, differences between allergic and healthy infants could simply reflect differences between nonfarming and farming diets. To address this problem, an OPLS-DA model (VIP $\geq 1.0$, one component, $R^{2}=0.24$ and $Q^{2}=0.39$ ) was made to evaluate maternal diet of allergic and nonallergic children in the nonfarming group only (Figure 3). Actual intakes are displayed in Tables 3 and 4. Maternal intake of margarine, as well as margarine and oils in total, remained strongly discriminatory variables in the OPLS-DA model, both during pregnancy and lactation. Mothers of allergic infants consumed significantly more margarine and margarine plus oils during lactation than mothers of healthy infants $(P=0.03$ 
Table 2. Intake of food items during pregnancy and lactation ${ }^{\mathrm{b}}$ in mothers of farm and nonfarm children

\begin{tabular}{|c|c|c|c|c|c|c|}
\hline \multirow[b]{2}{*}{ Food item (g/d) } & \multicolumn{3}{|c|}{ Pregnancy $^{c}$} & \multicolumn{3}{|c|}{ Lactation $^{d}$} \\
\hline & Farmers $(n=21)$ & Nonfarmers $(n=36)$ & $p^{e}$ & Farmers $(n=19)$ & Nonfarmers $(n=25)$ & pe \\
\hline Butter ${ }^{f}$ & $13(2-14)$ & $1(0-13)$ & 0.02 & $6(0-20)$ & $0(0-10)$ & 0.13 \\
\hline Margarine & $0(0-4)$ & $12(0-16)$ & 0.001 & $1(0-11)$ & $11(0-20)$ & 0.14 \\
\hline Olive oil & $0(0-1)$ & $1(0-2)$ & 0.01 & $0(0-0)$ & $0(0-0)$ & 0.53 \\
\hline Rapeseed oil & $2(0-3)$ & $0(0-2)$ & 0.51 & $0(0-2)$ & $0(0-0)$ & 0.08 \\
\hline Other oils & $0(0-0)$ & $0(0-0)$ & 0.56 & $0(0-0)$ & $0(0-0)$ & 0.38 \\
\hline Oils total & $2(1-3)$ & $2(3-1)$ & 0.39 & $0(0-3)$ & $0(0-2)$ & 0.65 \\
\hline Margarine and oils & $4(3-6)$ & $13(6-17)$ & $<0.001$ & $3.0(2-14)$ & $11(2-31)$ & 0.20 \\
\hline Milk $^{g} \leq 1.5 \%$ fat & $110(0-340)$ & $360(210-640)$ & 0.009 & $0(0-200)$ & $130(0-290)$ & 0.10 \\
\hline Milk $^{g}>1.5 \%$ fat & $180(71-350)$ & $89(16-250)$ & 0.10 & $250(100-400)$ & $63(30-240)$ & 0.02 \\
\hline Milk $^{g}$ total & $440(270-570)$ & $520(330-790)$ & 0.13 & $420(200-520)$ & $250(130-430)$ & 0.21 \\
\hline Cream $^{\mathrm{h}}=8-15 \%$ fat & $2(1-10)$ & $9.0(3.6-16)$ & 0.01 & $0(0-20)$ & $0(0-15)$ & 0.97 \\
\hline Cream $^{\mathrm{h}}=27-40 \%$ fat & $4(2-10)$ & $2.1(0-4.5)$ & 0.06 & $7(0-38)$ & $0(0-15)$ & 0.30 \\
\hline Cream $^{\mathrm{h}}$ total & $10(4-22)$ & $13(4-21)$ & 0.89 & $25(0-60)$ & $15(0-30)$ & 0.26 \\
\hline Cheese $<20 \%$ fat & $0(0-0)$ & $0(0-1)$ & 0.13 & $0(0-0)$ & $0(0-0)$ & 0.21 \\
\hline Cheese $\geq 20 \%$ fat & $14(3-20)$ & $14(7-20)$ & 0.54 & $30(8-70)$ & $25(5-40)$ & 0.39 \\
\hline Cheese total & $20(7-22)$ & $28(17-47)$ & 0.19 & $30(8-70)$ & $25(15-45)$ & 0.66 \\
\hline Fatty fish & $6.3(0-9.0)$ & $6(3-11)$ & 0.62 & $0(0-0)$ & $0(0-0)$ & 0.58 \\
\hline Lean fish & $11(5.4-21)$ & $11(5-21)$ & 0.44 & $0(0-0)$ & $0(0-0)$ & 0.04 \\
\hline Shellfish & $0(0-3)$ & $3(0-5)$ & 0.44 & $0(0-0)$ & $0(0-0)$ & 1.0 \\
\hline Seafood total & $20(11-29)$ & $22(15-29)$ & 0.76 & $0(0-30)$ & $0(0-0)$ & 0.48 \\
\hline Fatty pork & $34(25-63)$ & $42(28-51)$ & 0.44 & $54(0-94)$ & $22(0-54)$ & 0.13 \\
\hline
\end{tabular}

Data are presented as medians (interquartile range).

aMeasured by food frequency questionnaire. ${ }^{b}$ Measured by 24-h recall followed by 24-h food diary 4 mo postpartum. ${ }^{\circ}$ Eight subjects (7 farmers) lacked maternal dietary data during pregnancy. ${ }^{\top}$ Twenty-one subjects excluded: 12 ( 5 farmers) were no longer breast fed and 9 (4 farmers) lacked maternal dietary data during lactation. ${ }^{e}$ Mann-Whitney U-test comparing

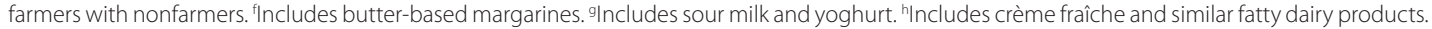

for both); the same tendency was seen during pregnancy $(P=$ 0.17 and 0.052, respectively; Figure 3, Tables 3 and 4). Higher breast milk proportions of DHA in mothers of healthy children tended to remain after exclusion of farmers $(0.3$ vs. $0.2 \%$, $P=0.09$ ), as did the lower ratio of arachidonic acid to DHA (1.4 vs. $2.0, P=0.052)$.

Multivariable analysis. Logistic regression with margarine and oil intake during pregnancy or lactation as explanatory variables and allergy as outcome was performed on nonfarmers. Variables were included as covariates if $P \leq 0.2$ in univariable analysis, i.e., duration of exclusive and partial breast-feeding $(P=0.02$ and 0.04 , respectively), maternal heredity $(P=0.11)$, gestational weight $(P=0.18)$, and cesarean section $(P=0.17$; Table 1). Due to the small group of allergic subjects $(n=10)$, the covariates were entered independently in separate models (Table 5). Since only one farm child developed allergy, the models included nonfarmers only, to avoid confounding between being healthy and being raised on a farm. The crude odds ratio for every portion of margarine and oil consumed per day ( 1 portion $=5 \mathrm{~g}$, Swedish National Food Agency, 2001) was 1.91 (95\% confidence interval: $1.02-3.56, P=0.04)$ during pregnancy and 1.50 (95\% confidence interval: $1.02-2.21$,
$P=0.04)$ during lactation (Table 5). The odds ratios did not decrease substantially in any of the adjusted models, suggesting little influence of covariates (Table 5).

\section{Correlations Between Intake of Food Items and Breast Milk Fatty Acids}

A selection of correlations between the intake of food items during pregnancy and lactation and proportions of fatty acids in breast milk at 4 mo postpartum is presented in Table 6 . Intake of margarine and oils reported during pregnancy correlated with the proportion of both linoleic and alpha-linolenic acid in breast milk ( $P=0.02$ for both); the same tendency was observed during lactation ( $P=0.17$ and 0.06 , respectively). Alpha-linolenic acid in breast milk correlated with margarine intake alone, both during pregnancy and lactation $(P=0.03$ and 0.02 , respectively); this was the case also for correlations between the reported intake of fatty fish and DHA in breast milk ( $P=0.02$ and 0.01 , respectively).

\section{DISCUSSION}

Children raised on farms are known to have reduced risk of developing allergy (2-5). Despite the small cohort studied here, we found a significant protection of living on a small dairy farm, 


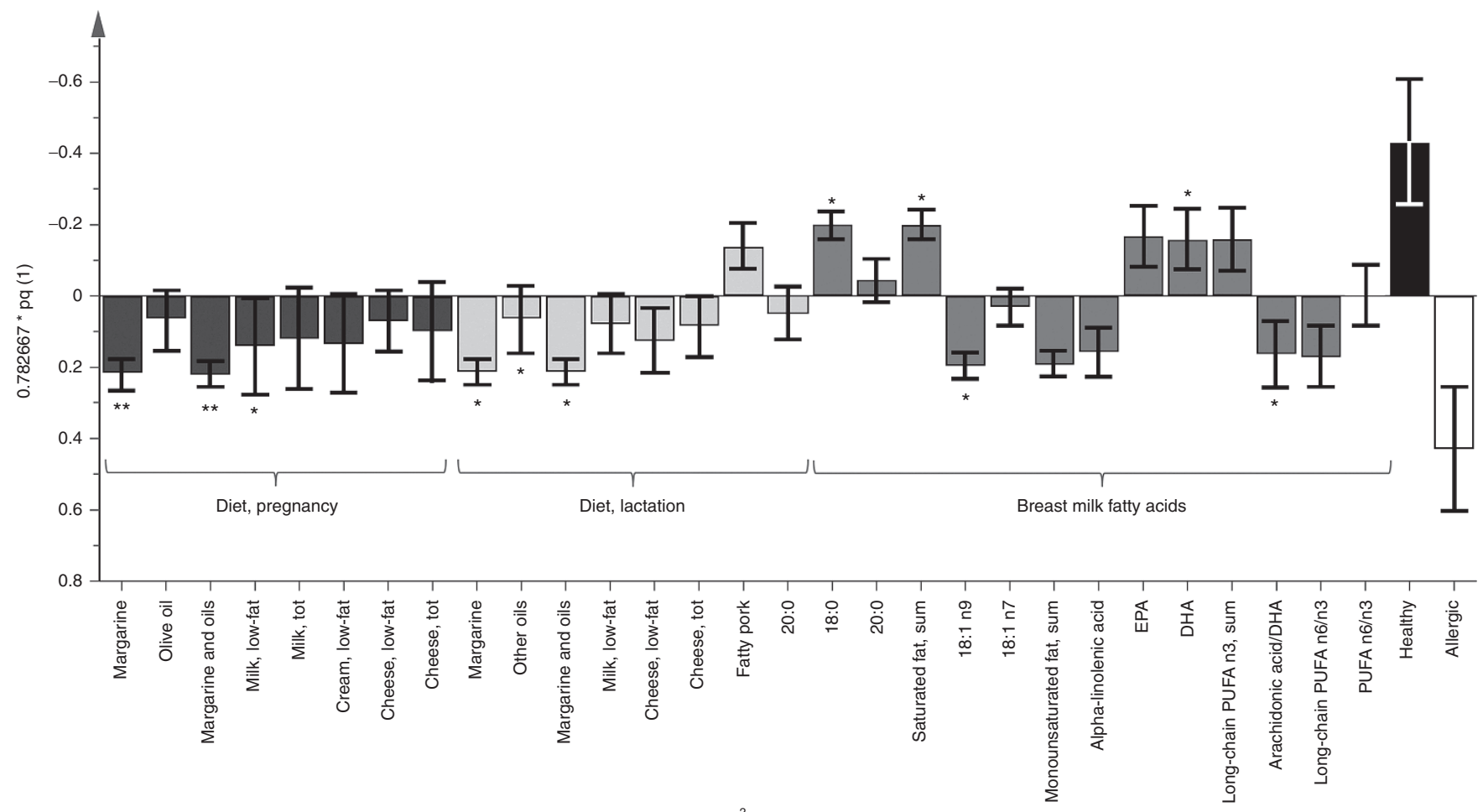

$R^{2} \times(1)=0.235$

Figure 2. Diet and breast milk fatty acid composition of mothers of healthy and allergic children. For interpretation and explanations, see Figure 1. One component is included in this loading plot; Variable Influence on Projection $\geq 1, R^{2}=0.24$ and $Q^{2}=0.39 . n$ (dietary data, pregnancy) $=39 \mathrm{for}$ healthy and 11 for allergic; $n$ (dietary data, lactation) $=31$ for healthy and 7 for allergic; $n$ (breast milk data) $=25$ for healthy and 5 for allergic. ${ }^{*} P \leq 0.05,{ }^{* *} P \leq 0.01$. DHA, docosahexaenoic acid; EPA, eicosapentaenoic acid; PUFA, polyunsaturated fatty acid.

Table 3. Intake ${ }^{a}$ of food items during pregnancy in mothers of healthy and allergic children

\begin{tabular}{|c|c|c|c|c|c|c|}
\hline \multirow[b]{2}{*}{ Food item (g/d) } & \multicolumn{3}{|c|}{ All subjects $^{\mathrm{b}}$} & \multicolumn{3}{|c|}{ Nonfarmers ${ }^{c}$} \\
\hline & Healthy $(n=39)$ & Allergic $(n=11)$ & $P^{d}$ & Healthy $(n=21)$ & Allergic $(n=10)$ & $P^{d}$ \\
\hline Butter $^{\mathrm{e}}$ & $4(0-13)$ & $5(0-13)$ & 0.77 & $0(0-5)$ & $3(0-13)$ & 0.46 \\
\hline Margarine & $4(0-13)$ & $13(5-18)$ & 0.01 & $7(0-15)$ & $13(12-18)$ & 0.17 \\
\hline Olive oil & $0(0-2)$ & $2(0-2)$ & 0.23 & $1(0-2)$ & $2(0-2)$ & 0.36 \\
\hline Rapeseed oil & $1(0-2)$ & $0(0-5)$ & 0.82 & $0(0-2)$ & $0(0-5)$ & 0.71 \\
\hline Other oils & $0(0-0.1)$ & $0(0-0)$ & 0.55 & $0(0-0)$ & $0(0-0)$ & 0.55 \\
\hline Milk $^{\dagger} \leq 1.5 \%$ fat & $350(32-440)$ & $500(200-1,000)$ & 0.02 & $330(220-590)$ & $500(400-1,000)$ & 0.08 \\
\hline Milk $^{f}>1.5 \%$ fat & $89(180-250)$ & $36(0-250)$ & 0.40 & $89(18-180)$ & $25(0-250)$ & 0.73 \\
\hline Milk total & $450(250-590)$ & $750(270-1,300)$ & 0.09 & $460(310-640)$ & $750(400-1,000)$ & 0.10 \\
\hline Cream $^{9}=8-15 \%$ fat & $4(2-10)$ & $12(1-18)$ & 0.12 & $9(4-15)$ & $14(9-18)$ & 0.26 \\
\hline Cream $^{g}=27-40 \%$ fat & $2(0-5)$ & $4(0-9)$ & 0.43 & $1(0-4)$ & $4(0-9)$ & 0.17 \\
\hline Cheese total & 20 (7-29) & $20(17-50)$ & 0.23 & $20(9-29)$ & $21(17-50)$ & 0.24 \\
\hline Fatty fish & $8(2-11)$ & $4(0-9)$ & 0.20 & $8(4-18)$ & $4(0-9)$ & 0.18 \\
\hline Lean fish & $11(5-21)$ & $11(5-21)$ & 0.75 & $11(5-11)$ & $11(5-21)$ & 0.63 \\
\hline Shellfish & $3(0-6)$ & $0(0-3)$ & 0.33 & $3(0-6)$ & $2(0-3)$ & 0.23 \\
\hline Seafood total & $25(12-30)$ & $20(11-23)$ & 0.41 & $26(18-30)$ & $21(18-23)$ & 0.27 \\
\hline Fatty pork & $36(25-47)$ & $40(39-65)$ & 0.24 & $45(28-47)$ & $40(39-49)$ & 0.77 \\
\hline
\end{tabular}

Data are presented as medians (interquartile range).

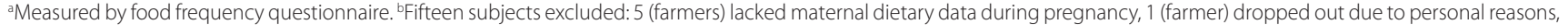
1 (nonfarmer) changed residence, 7 ( 2 farmers) were allergic at 1.5 y but not 3 y, and 1 (farmer) lacked allergy diagnosis at 3 y. 'Six subjects excluded: 1 changed residence and 5 were

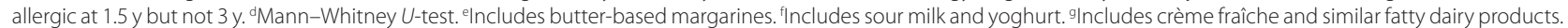


Table 4. Intake $e^{a}$ of food items during lactation in mothers of healthy and allergic children

\begin{tabular}{|c|c|c|c|c|c|c|}
\hline \multirow[b]{2}{*}{ Food item (g/d) } & \multicolumn{3}{|c|}{ All subjects ${ }^{b}$} & \multicolumn{3}{|c|}{ Nonfarmers ${ }^{c}$} \\
\hline & Healthy $(n=31)$ & Allergic $(n=7)$ & $P^{d}$ & Healthy $(n=14)$ & Allergic $(n=6)$ & $p^{e}$ \\
\hline Butter ${ }^{c}$ & $1(0-17)$ & $0(0-27)$ & 0.98 & $0(0-14)$ & $0(0-9)$ & 1.0 \\
\hline Margarine & $3(0-15)$ & $20(11-40)$ & 0.02 & $9(0-15)$ & $28(14)$ & 0.03 \\
\hline Olive oil & $0(0-0)$ & $0(0-0)$ & 0.82 & $0(0-0)$ & $0(0-0)$ & 0.79 \\
\hline Rapeseed oil & $0(0-2)$ & $0(0-0)$ & 0.47 & $0(0-0)$ & $0(0-0)$ & 0.89 \\
\hline Other oils & $0(0-0)$ & $0(0-0)$ & 0.04 & $0(0-0)$ & $0(0-0)$ & 0.13 \\
\hline Oils total & $0(0-3)$ & $0(0-4)$ & 0.80 & $0(0-2)$ & $1(0-4)$ & 0.38 \\
\hline Margarine and oils & $5(2-15)$ & $31(13-40)$ & 0.04 & $9(2-20)$ & $33(14-40)$ & 0.03 \\
\hline Milk $^{f} \leq 1.5 \%$ fat & $95(0-250)$ & $210(100-400)$ & 0.11 & $110(0-280)$ & $310(110-400)$ & 0.08 \\
\hline Milk $^{f}>1.5 \%$ fat & $180(38-350)$ & $30(0-260)$ & 0.14 & $81(35-180)$ & $30(0-260)$ & 0.28 \\
\hline Milk total & $380(180-500)$ & $240(100-660)$ & 0.87 & $260(130-420)$ & $360(110-660)$ & 0.56 \\
\hline $\mathrm{Cream}^{9}=8-15 \%$ fat & $0(0-15)$ & $0(0-18)$ & 0.83 & $0(0-15)$ & $8(0-18)$ & 0.71 \\
\hline Cream $^{g}=27-40 \%$ fat & $3(0-26)$ & $0(0-30)$ & 0.86 & $1(0-15)$ & $8(0-30)$ & 0.57 \\
\hline Cream $^{9}$ total & $15(0-38)$ & $15(0-30)$ & 1.0 & $1(0-34)$ & $20(15-30)$ & 0.34 \\
\hline Cheese $<20 \%$ fat & $0(0-0)$ & $0(0-0)$ & 0.22 & $0(0-0)$ & $0(0-0)$ & 0.48 \\
\hline Cheese $\geq 20 \%$ fat & $30(5-59)$ & $20(0-0)$ & 0.58 & $24(5-40)$ & $10(0-30)$ & 0.34 \\
\hline Cheese total & $30(5-60)$ & $30(0-93)$ & 0.69 & $24(5-45)$ & $25(0-93)$ & 0.97 \\
\hline Fatty fish & $0(0-0)$ & $0(0-0)$ & 0.26 & $16(0-0)$ & $0(0-0)$ & 0.23 \\
\hline Lean fish & $0(0-0)$ & $0(0-0)$ & 0.50 & $0(0-0)$ & $0(0-0)$ & 1.0 \\
\hline Shellfish & $0(0-0)$ & $0(0-0)$ & 1.0 & $0(0-0)$ & $0(0-0)$ & 1.0 \\
\hline Seafood total & $0(0-0)$ & $0(0-0)$ & 0.17 & $16(0-0)$ & $0(0-0)$ & 0.23 \\
\hline Fatty pork & $47(0-88)$ & $0(0-39)$ & 0.10 & $47(0-75)$ & $12(0-31)$ & 0.08 \\
\hline
\end{tabular}

Data are presented as medians (interquartile range).

${ }^{\mathrm{a}}$ Measured by 24 -h recalls followed by 24 -h food diaries 4 mo postpartum. ${ }^{b}$ Twenty-seven subjects excluded: 12 ( 5 farmers) were no longer breast fed, 7 (2 farmers) lacked maternal dietary data during lactation, 7 ( 2 farmers) were allergic at 1.5 y but not 3 y, and 1 (farmer) lacked allergy diagnosis at 3 y. ‘Seventeen subjects excluded: 8 were no longer breast fed, 4 lacked maternal dietary data during lactation, and 5 were allergic at 1.5 y but not 3 y. ${ }^{\mathrm{d}}$ Mann-Whitney $U$-test. Includes butter-based margarines. Includes sour milk and yoghurt.

Includes crème fraîche and similar fatty dairy products.

a finding previously reported (11). Our hypothesis was that this partly could be explained by differences in fat composition of diet and breast milk of farming and nonfarming mothers.

Farming mothers reported a higher consumption of full-fat dairy products and saturated fats as well as a lower intake of margarine and oils. Mothers of allergic children were found to have a higher intake of margarine and oils than mothers of healthy children; the odds ratios did not decrease substantially by the influence of covariates, neither during pregnancy nor lactation. High margarine intake in pregnant women has previously been shown to be associated with eczema in their 2-y-old offspring (12), and maternal margarine intake during lactation has been reported to be a weak risk factor for asthma in the children at $5 \mathrm{y}$ of age (13). Moreover, margarine intake in childhood has been associated with different allergies (1420 ), as has consumption of margarine in adolescent/adulthood (21-23); while other studies have failed to find such associations (24-30).

The differences in maternal dietary habits between farm and nonfarm children observed in our study are in line with those previously reported in a Finnish study, where lower consumption of margarine and low-fat milk and higher intake of butter and whole milk were observed in 6- to 13-y-old farm children compared with nonfarm children (8). However, allergy prevalence was not examined in the Finnish study and fatty acid consumption not evaluated. Sensitization (production of $\operatorname{IgE}$ antibodies as reflected in skin prick test) was inversely related to regular animal contact but not linked to a specific food item (8). Accordingly, we found no relation between dietary fats and the degree of sensitization in our study (data not shown) and sensitization was equally prevalent in the farming and nonfarming group (11).

Possible alternate factors explaining the association found between margarine and oil intake and allergy in the nonfarming mothers should be considered. Families that consume margarine and oils instead of butter might be families that are more prone to follow dietary guidelines, which in turn might be families with higher socioeconomic status. High socioeconomic status have been associated with higher risk of allergy development, possibly explained by limited microbial stimuli that may be important for proper maturation of the immune system according to the "hygiene hypothesis." In our study, socioeconomic status was measured by educational level. The educational level of allergic nonfarming fathers was insignificantly higher than that of healthy nonfarming fathers. However, the opposite was found for mothers, i.e., the educational level 


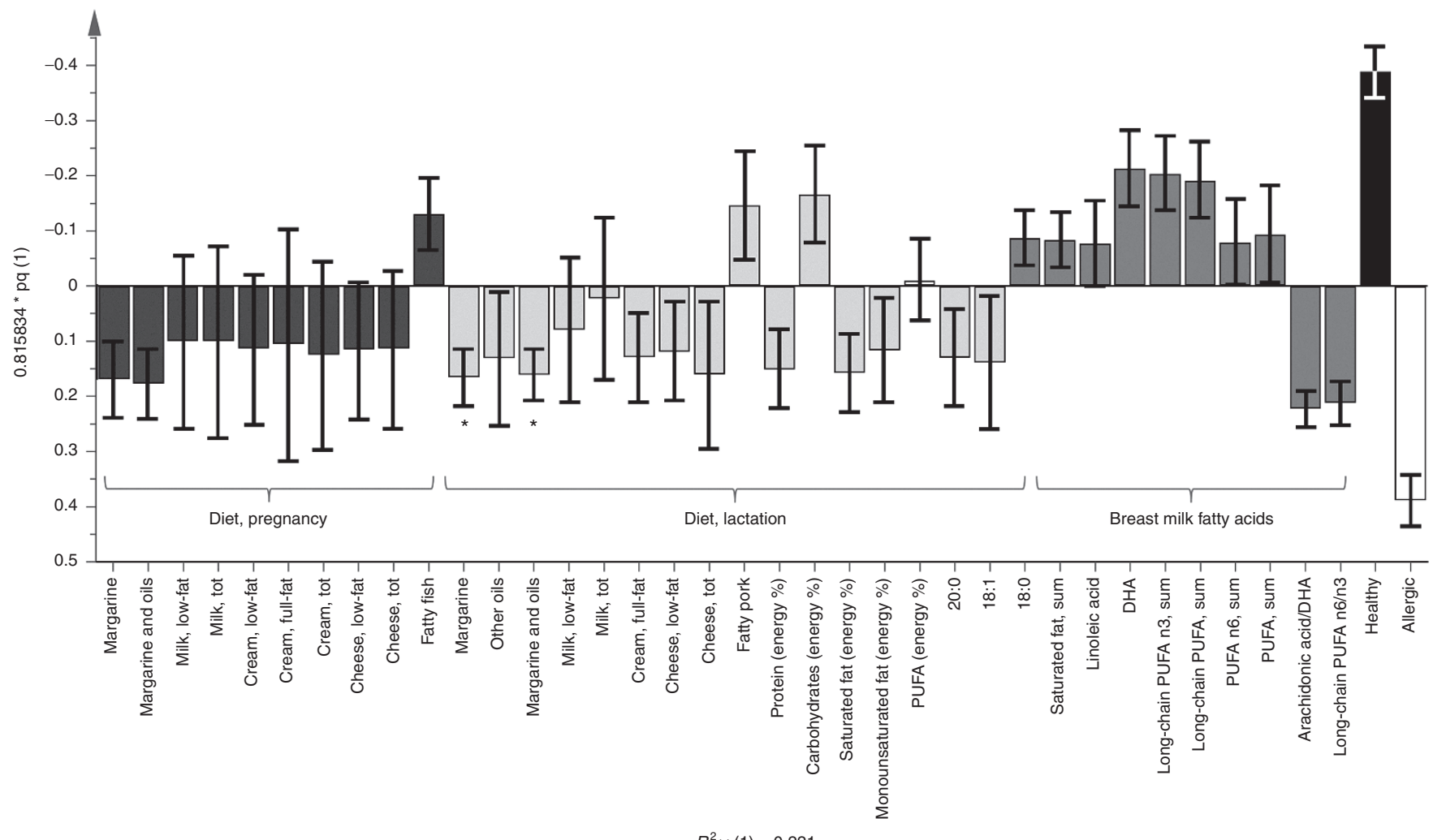

Figure 3. Diet and breast milk fatty acid composition of nonfarming mothers of healthy and allergic children. For interpretation and explanations, see Figure 1. One component is included in this loading plot; Variable Influence on Projection $\geq 1, R^{2}=0.22$ and $Q^{2}=0.40 . n$ (dietary data, pregnancy) $=$ 21 for healthy and 10 for allergic; $n$ (dietary data, lactation) $=14$ for healthy and 6 for allergic; $n$ (breast milk data) $=12$ for healthy and 4 for allergic. ${ }^{*} P \leq$ 0.05. DHA, docosahexaenoic acid; PUFA, polyunsaturated fatty acid.

Table 5. Logistic regression models of maternal total intake of margarine and oils during pregnancy and lactation and allergy in the child at age 3 y of age

\begin{tabular}{|c|c|c|c|c|c|c|}
\hline \multirow[b]{2}{*}{ Predictor variable } & \multicolumn{3}{|c|}{ Pregnancy $(n=31)$} & \multicolumn{3}{|c|}{ Lactation $(n=20)$} \\
\hline & OR & $95 \% \mathrm{Cl}$ & $P$ & OR & $95 \% \mathrm{Cl}$ & $P$ \\
\hline Margarine and oils alone & 1.91 & $1.02-3.56$ & 0.04 & 1.50 & $1.02-2.21$ & 0.04 \\
\hline Margarine and oils & 1.91 & $0.94-3.88$ & 0.08 & 1.86 & $1.02-3.40$ & 0.04 \\
\hline Exclusive breastfeeding & 0.53 & $0.30-0.93$ & 0.03 & 0.38 & $0.13-1.07$ & 0.07 \\
\hline Partial breastfeeding & 0.77 & $0.59-1.00$ & 0.05 & 0.51 & $0.27-1.06$ & 0.07 \\
\hline \multicolumn{7}{|l|}{ Model 3} \\
\hline Margarine and oils & 1.73 & $0.89-3.37$ & 0.11 & 1.47 & $0.97-2.21$ & 0.07 \\
\hline Maternal heredity & 2.38 & $0.39-15.66$ & 0.35 & 3.85 & $0.38-39.56$ & 0.26 \\
\hline \multicolumn{7}{|l|}{ Model 5} \\
\hline Margarine and oils & 2.31 & $1.09-4.87$ & 0.03 & 1.72 & $1.04-2.84$ & 0.04 \\
\hline Cesarean section & 8.04 & $0.97-66.69$ & 0.053 & $11.67 \hat{A} \hat{A}$ & $0.46-290.60$ & 0.14 \\
\hline
\end{tabular}

ORs and Cls for every portion ( $5 \mathrm{~g}$ ) of margarine and oil consumed per day. Variables with $P \leq 0.2$ in univariable analysis are included as covariates in separate models. $\mathrm{Cl}$, confidence interval; OR, odds ratio.

${ }^{a} n=30$ and 19 during pregnancy and lactation, respectively. 
Table 6. Correlations between maternal consumption of food items during pregnancy and lactation ${ }^{\mathrm{b}}$ and fatty acid proportions in breast milk ${ }^{\mathrm{c}}$

\begin{tabular}{|c|c|c|c|c|c|c|}
\hline \multirow[b]{2}{*}{ Breast milk fatty acid } & \multicolumn{3}{|c|}{ Intake during pregnancy $\left(n=29^{d}\right)$} & \multicolumn{3}{|c|}{ Intake during lactation $\left(n=26^{d}\right)$} \\
\hline & Margarine ${ }^{e}$ & Margarine and oils & Fatty fish & Margarine $^{\mathrm{e}}$ & Margarine and oils & Fatty fish \\
\hline $18: 1 n-9$ & $0.45(0.01)$ & $0.22(0.26)$ & $0.28(0.14)$ & $0.38(0.06)$ & $0.45(0.02)$ & $-0.43(0.03)$ \\
\hline Linoleic acid $(n-6)$ & $0.35(0.06)$ & $0.43(0.02)$ & $0.19(0.33)$ & $0.29(0.15)$ & $0.28(0.17)$ & $0.03(0.90)$ \\
\hline Alpha-linolenic acid ( $n-3)$ & $0.41(0.03)$ & $0.42(0.02)$ & $0.42(0.02)$ & $0.44(0.02)$ & $0.37(0.06)$ & $0.05(0.80)$ \\
\hline DHA & $-0.36(0.05)$ & $-0.23(0.22)$ & $0.43(0.02)$ & $-0.14(0.49)$ & $0.01(0.97)$ & $0.46(0.01)$ \\
\hline Total long-chain PUFA & $-0.37(0.04)$ & $-0.26(0.16)$ & $0.29(0.12)$ & $-0.02(0.91)$ & $0.09(0.65)$ & $0.49(0.01)$ \\
\hline Total PUFA & $0.28(0.14)$ & $0.38(0.04)$ & $0.21(0.26)$ & $0.30(0.13)$ & $0.28(0.17)$ & $0.21(0.30)$ \\
\hline
\end{tabular}

Data are presented as Spearman's rho (Pvalue); both farmers and nonfarmers are included. DHA, docosahexaenoic acid; $n$, omega; PUFA, polyunsaturated fatty acid.

${ }^{a}$ Measured by food frequency questionnaire. ${ }^{b}$ Measured by $24-\mathrm{h}$ recall followed by $24-\mathrm{h}$ food diary 4 mo postpartum. ${ }^{C}$ Expressed in conjunction with the dietary assessment 4 mo

postpartum. ${ }^{\mathrm{d}}$ For DHA and total long-chain PUFA, $n=31$ and 28 during pregnancy and lactation, respectively. ${ }^{\mathrm{e}}$ Excludes butter-based margarines.

of allergic nonfarming mothers was insignificantly lower than that of healthy nonfarming mothers. Since the $P$ values were higher than 0.2 , educational level was not considered to be a potential confounder for the relationship between margarine and oil intake and allergy development.

We found maternal consumption of margarine and oils to correlate moderately with breast milk proportions of the PUFAs linoleic acid (n-6), alpha-linoleic acid ( $n-3)$, and the monounsaturated fatty acid 18:1 (n-9), which are found in relatively large quantities in margarines and oils. Mothers of allergic children had higher proportions of 18:1 n-9 in breast milk compared with mothers of healthy children. This was, however, not observed when nonfarmers where compared with farmers.

Maternal and children's intake of fish has repeatedly been found to be inversely associated with allergy development (27,31-33). In our study, breast milk proportions of the long-chain omega-3 fatty acid DHA (mainly found in fatty fish) were significantly higher in mothers of healthy children than in mothers of allergic children. The association weakened when only nonfarmers were analyzed; this is likely due to a decrease in power as a result of the decreased study sample, since no difference in breast milk proportions of DHA was found between farming and nonfarming mothers. The proportions of DHA in breast milk correlated with consumption of fatty fish, both during pregnancy and lactation. These findings might reflect a protective effect of high proportions of DHA in breast milk per se or a protective effect of maternal fish intake, mediated not only by long-chain PUFAs. Along this line, intake of fatty fish was insignificantly higher during pregnancy in mothers of healthy children.

The small study population is a limitation with respect to low power, which might explain the weak $P$ values for the differences in margarine and oil intake between mothers of healthy and allergic children. Also, in the context of multiple comparisons, false positives may be a problem and our results must be interpreted with caution. However, the small study sample has allowed us to collect detailed information of allergy diagnoses and fat composition of diet and breast milk as well as demographic data. Additionally, no information was collected on families that did not volunteer to participate in the study, hence differences between infants recruited to the FARMFLORA cohort compared with infants who were not recruited were not analyzed. A general assumption is that parental educational level might have been higher for those interested in participating in the study. However, we have no reason to believe that this would affect our conclusion, since parental educational level did not differ significantly between healthy and allergic infants according in our cohort.

Consumption of unpasteurized farm milk has been proposed to protect against allergy development $(6,7)$. According to the dietary assessments during lactation, none of the children in our study were given any form of farm milk during the first 4 mo. The Swedish National Food Agency strongly discourages intake of unpasteurized milk, especially in children, as do well-baby clinics, due to the risk of infection. Half of the farming mothers reported consumption of farm milk. However, as only a single child in the farming group developed allergy, we could not examine whether maternal intake of fresh farm milk contributed to the allergy protection.

In conclusion, our results suggest that a maternal diet low in margarine and oils to a moderate extent may contribute to the allergy-protective effect of growing up on dairy farms. Current dietary recommendations for pregnant women include an exchange of saturated for unsaturated fats, which might lead to an increased consumption of margarines and oils. Intervention studies of margarine and oil consumption during pregnancy and lactation are warranted to evaluate a causal relationship with allergy development in the offspring.

\section{METHODS}

\section{Subjects}

The FARMFLORA birth cohort comprises 28 infants raised on small family-owned dairy farms and 37 infants from rural resident nonfarming families, in the Skaraborg County in South-West Sweden. Pregnant women were recruited at maternity clinics between September 2005 and May 2008. Children born at term (gestational week 36-42) were included after written informed consent from both parents. Subjects from dairy farms with infrequent animal contact, from farming milieus other than dairy farms, or urban milieus were excluded. The study was approved by the Regional Ethics Committee in Gothenburg (No. 363-05).

\section{Dietary Assessment}

The mothers' food intake during pregnancy was reported in a semiquantitative food frequency questionnaire, which was mailed shortly after delivery. The questionnaire was based on the Northern Sweden 84-item food frequency questionnaire (34), extended to comprise approximately twice as many food items as the original version to capture details about, e.g., fat-containing foods (35). Frequencies were 
reported on a nine-level scale: never/seldom, once a month, twice a month, once a week, two to three times a week, four to six times a week, once a day, two to three times a day, and more than or equal to four times a day. Frequencies were converted to intake in grams per day based on reported portion sizes or, when not reported, standard portion sizes according to the Swedish National Food Agency (2001).

Maternal diet during lactation was assessed 4 mo after delivery by a 24 -h dietary recall, followed by a 24 -h food diary. The recalls were performed as telephone interviews using a modified version of the US Department of Agriculture's five-step multiple-pass method (36) including questions about (i) all foods and beverages consumed during the past $24 \mathrm{~h}$, (ii) foods often forgotten, (iii) time and occasion of the afore mentioned food intake, (iv) portion sizes and amounts of all ingested foods and beverages; household measures were used instead of food model booklets. The fifth step included in the original method (final probe review) was excluded to facilitate the interview.

The following $24 \mathrm{~h}$, food diaries were performed. Participants were instructed to maintain their regular dietary habits and register in detail everything consumed during the $24 \mathrm{~h}$.

Nutrient and energy composition of the diet during lactation was calculated based on the food composition database of the Swedish National Food Agency (2007) using the software Diet 32 (Aivo AB, Stockholm, Sweden; 11 April 2008).

Collection of Breast Milk and Analysis of Fatty Acid Composition Four months postpartum, $\sim 5 \mathrm{ml}$ of breast milk was expressed manually, in conjunction with a breast-feeding meal at any time of the day. Samples were directly frozen at $-20^{\circ} \mathrm{C}$ in sterile plastic tubes and transferred to storage at $-80^{\circ} \mathrm{C}$ within 6 mo after collection.

Fatty acids in the total lipid fraction of breast milk were analyzed by gas chromatography after conversion to methyl esters (37), as earlier described (28). Two columns were used: a fused silica SPB-5 $\left(30-\mathrm{m} \times 0.25-\mathrm{mm} \times 0.25-\mu \mathrm{m} \mathrm{d}_{\mathrm{F}}\right)$ column (Supelco, Bellefonte, PA), suitable for separation of 20-22 carbon atoms long fatty acids, and a DB-WAX $\left(30-\mathrm{m} \times 0.25-\mathrm{mm} \times 0.25-\mu \mathrm{m} \mathrm{d}_{\mathrm{F}}\right)$ column $(J \& W$ Scientific, Folsom, CA), suitable for separation of 16-18 carbon long fatty acids. Detection was done by flame ionization and the Borwin software (JMBS Developpements, Le Fontanil, France) was used for evaluation.

\section{Clinical Examination}

The children were clinically examined by pediatricians at 1.5 and $3 \mathrm{y}$ of age to diagnose food allergy, eczema, asthma, and allergic rhinoconjunctivitis according to predefined protocols (38). Sensitization against common food (6-mix food) and inhalant allergens (Phadiatop) were assessed by blood tests (Phadia, Uppsala, Sweden). Atopic eczema was diagnosed according to William's criteria (39); for a diagnosis at $3 \mathrm{y}$ of age, symptoms had to be present after age $2 \mathrm{y}$. Food allergy was defined based on immediate or late-onset reactions that rapidly improved after allergen elimination. The diagnosis was supported by open food challenge tests and/or positive 6-mix food test (Phadia), followed by ImmunoCAP tests (Phadia) for identification of the relevant allergen. Asthma was diagnosed based on either persistent wheezing for $\geq 4$ wk or more than or equal to three wheezing episodes combined with either: (i) eczema, allergic rhinoconjunctivitis, or food allergy or (ii) a response to leukotriene antagonists or inhaled glucocorticoids. For an asthma diagnosis at $3 \mathrm{y}$ of age, at least one wheezing episode had to have occurred after 2 y of age. Allergic rhinoconjunctivitis was defined as eye or nose symptoms after exposure to pollen or animal dander, combined with demonstration of allergen-specific IgE test to the corresponding inhalant allergen (Phadiatop; Phadia).

\section{Statistical Methods}

Multivariate analysis. Orthogonal projections to latent structures with discriminant analysis (OPLS-DA) (40) was used to visualize dietary and breast milk fatty acid patterns in farming and nonfarming mothers, as well as mothers of healthy and allergic children (Simca 13.0; Umetrics, Umeå, Sweden). In OPLS-DA, separation of the subjects into predetermined groups (e.g., farmers and nonfarmers) is attempted based on a large number of variables. The contribution of each variable to the separation of the groups, i.e., the VIP value, was calculated for all models. Variables with a VIP value less than 1.0 were discarded and new models were generated based on the remaining variables. The discriminatory power of the variables is displayed in one-dimensional loading plots; error bars denote the $95 \%$ confidence level, computed by jack-knifing (estimation of bias and variance based on subsets of the available data). Model validation was performed by cross-validation. In OPLS-DA, the y-variable is a dummy vector of zeros and ones, describing the samples' class affiliation. High cumulative fractions of variance of y explained $\left(\mathrm{R}^{2}\right)$ and predicted by cross-validation $\left(\mathrm{Q}^{2}\right)$ are measures of quality of the model (the closest to one the better). Moreover, in OPLS, large numbers of variables in a moderate number of observations can be analyzed. The variables need neither to be normally distributed, nor independent of one another (41).

Univariable analysis. Due to small sample sizes and nonnormal distributions of the variables in general, nonparametric tests were used. Diet and breast milk variables were tested for significance using Mann-Whitney $U$-test. Correlations were calculated by Spearman's rho. Participant characteristics were analyzed using $\chi^{2}$ test or Fisher's exact test for categorical variables and Mann-Whitney $U$-test for continuous variables. Two-tailed $P$ values of $\leq 0.05$ were considered significant. The analyses were performed with SPSS Statistics version 19 (IBM Corporation, New York, NY).

Multivariable analysis. Logistic regression was used for multivariable analysis (SPSS Statistics version 19; IBM Corporation).

\section{ACKNOWLEDGMENTS}

We thank study nurses Helen Andersson and Anders Nordberg for excellent coordination of sampling and questionnaires in the FARMFLORA study; the pediatricians Margareta Ceder, Gunhild Lindhagen, Stefan Stentoft, and Carl-Johan Törnhage for skillful clinical diagnoses of the children; and all the families for taking part in the FARMFLORA study. We also thank Nils-Gunnar Carlsson and Annette Almgren for technical assistance with the fatty acid analyses, as well as Eva Freihult, Rui Pinto (Bioinformatics Infrastructure for Life Sciences (BILS)) and Staffan Nilsson for statistical support.

\section{STATEMENT OF FINANCIAL SUPPORT}

This study was supported by grants from the Swedish Research Council for Environmental, Agricultural Sciences and Spatial Planning (Formas, No. 222-2004-1958), Livsmedelsacceleratorn, SP Food and Biosciences (Former Food and Health Concept Centre), Gothenburg Sweden, West Gothia Region (VGR), Torsten and Ragnar Söderberg Foundation, the Medical Faculty of the University of Gothenburg under the LUA agreement, and the Swedish Research Council (VR, No. 521-2013-3154).

Disclosure: There are no disclosures.

\section{REFERENCES}

1. Institute of Environmental Medicine. Miljöhälsorapport 2013. Stockholm, Sweden: Institute of Environmental Medicine, 2013.

2. Braun-Fahrländer C, Gassner M, Grize L, et al. Prevalence of hay fever and allergic sensitization in farmer's children and their peers living in the same rural community. SCARPOL team. Swiss Study on Childhood Allergy and Respiratory Symptoms with Respect to Air Pollution. Clin Exp Allergy 1999;29:28-34.

3. Remes ST, Koskela HO, Iivanainen K, Pekkanen J. Allergen-specific sensitization in asthma and allergic diseases in children: the study on farmers' and non-farmers' children. Clin Exp Allergy 2005;35:160-6.

4. Riedler J, Eder W, Oberfeld G, Schreuer M. Austrian children living on a farm have less hay fever, asthma and allergic sensitization. Clin Exp Allergy 2000;30:194-200.

5. Von Ehrenstein OS, Von Mutius E, Illi S, Baumann L, Böhm O, von Kries R. Reduced risk of hay fever and asthma among children of farmers. Clin Exp Allergy 2000;30:187-93.

6. Riedler J, Braun-Fahrländer C, Eder W, et al.; ALEX Study Team. Exposure to farming in early life and development of asthma and allergy: a crosssectional survey. Lancet 2001;358:1129-33.

7. Perkin MR, Strachan DP. Which aspects of the farming lifestyle explain the inverse association with childhood allergy? J Allergy Clin Immunol 2006;117:1374-81.

8. Remes ST, Iivanainen K, Koskela H, Pekkanen J. Which factors explain the lower prevalence of atopy amongst farmers' children? Clin Exp Allergy 2003;33:427-34. 


\section{Maternal fat intake, farming, and allergy}

9. Black PN, Sharpe S. Dietary fat and asthma: is there a connection? Eur Respir J 1997;10:6-12.

10. Sausenthaler S, Koletzko B, Heinrich J. Dietary fat intake and allergic diseases. Curr Nutr Food Sci 2006;2:351-9.

11. Strömbeck A, Rabe H, Lundell AC, et al. High proportions of FOXP3(+) CD25(high) $\mathrm{T}$ cells in neonates are positively associated with allergic sensitization later in childhood. Clin Exp Allergy 2014;44:940-52.

12. Sausenthaler S, Koletzko S, Schaaf B, et al.; LISA Study Group. Maternal diet during pregnancy in relation to eczema and allergic sensitization in the offspring at $2 \mathrm{y}$ of age. Am J Clin Nutr 2007;85:530-7.

13. Lumia M, Luukkainen P, Kaila M, et al. Maternal dietary fat and fatty acid intake during lactation and the risk of asthma in the offspring. Acta Paediatr 2012;101:e337-43.

14. Bolte G, Frye C, Hoelscher B, Meyer I, Wjst M, Heinrich J. Margarine consumption and allergy in children. Am J Respir Crit Care Med 2001;163:277-9.

15. Chatzi L, Apostolaki G, Bibakis I, et al. Protective effect of fruits, vegetables and the Mediterranean diet on asthma and allergies among children in Crete. Thorax 2007;62:677-83.

16. Dunder T, Kuikka L, Turtinen J, Räsänen L, Uhari M. Diet, serum fatty acids, and atopic diseases in childhood. Allergy 2001;56:425-8.

17. Farchi S, Forastiere F, Agabiti N, et al. Dietary factors associated with wheezing and allergic rhinitis in children. Eur Respir J 2003;22:772-80.

18. Waser M, Michels KB, Bieli C, et al.; PARSIFAL Study team. Inverse association of farm milk consumption with asthma and allergy in rural and suburban populations across Europe. Clin Exp Allergy 2007;37:661-70.

19. von Mutius E, Weiland SK, Fritzsch C, Duhme H, Keil U. Increasing prevalence of hay fever and atopy among children in Leipzig, East Germany. Lancet 1998;351:862-6.

20. Sausenthaler S, Kompauer I, Borte M, et al.; LISA Study Group. Margarine and butter consumption, eczema and allergic sensitization in children. The LISA birth cohort study. Pediatr Allergy Immunol 2006;17:85-93.

21. Bolte G, Winkler G, Hölscher B, Thefeld W, Weiland SK, Heinrich J. Margarine consumption, asthma, and allergy in young adults: results of the German National Health Survey 1998. Ann Epidemiol 2005;15:207-13.

22. Nagel G, Linseisen J. Dietary intake of fatty acids, antioxidants and selected food groups and asthma in adults. Eur J Clin Nutr 2005;59:8-15.

23. Takaoka M, Norback D. Diet among Japanese female university students and asthmatic symptoms, infections, pollen and furry pet allergy. Respir Med 2008;102:1045-54

24. Chatzi L, Torrent M, Romieu I, et al. Diet, wheeze, and atopy in school children in Menorca, Spain. Pediatr Allergy Immunol 2007;18:480-5.

25. Suárez-Varela MM, Alvarez LG, Kogan MD, et al. Diet and prevalence of atopic eczema in 6 to 7 -year-old schoolchildren in Spain: ISAAC phase III. J Investig Allergol Clin Immunol 2010;20:469-75.

26. Wijga AH, Smit HA, Kerkhof M, et al.; PIAMA. Association of consumption of products containing milk fat with reduced asthma risk in pre-school children: the PIAMA birth cohort study. Thorax 2003;58: $567-72$.

27. Willers SM, Devereux G, Craig LC, et al. Maternal food consumption during pregnancy and asthma, respiratory and atopic symptoms in 5-year-old children. Thorax 2007;62:773-9.

28. Johansson S, Wold AE, Sandberg AS. Low breast milk levels of long-chain n-3 fatty acids in allergic women, despite frequent fish intake. Clin Exp Allergy 2011;41:505-15.

29. Barman M, Jonsson K, Sandin A, Wold AE, Sandberg AS. Serum fatty acid profile does not reflect seafood intake in adolescents with atopic eczema. Acta Paediatr 2014;103:968-76.

30. Nwaru BI, Erkkola M, Lumia M, et al. Maternal intake of fatty acids during pregnancy and allergies in the offspring. Br J Nutr 2012;108:720-32.

31. Dotterud CK, Storrø O, Simpson MR, Johnsen R, Øien T. The impact of pre- and postnatal exposures on allergy related diseases in childhood: a controlled multicentre intervention study in primary health care. BMC Public Health 2013;13:123.

32. Hesselmar B, Saalman R, Rudin A, Adlerberth I, Wold A. Early fish introduction is associated with less eczema, but not sensitization, in infants. Acta Paediatr 2010;99:1861-7.

33. Kull I, Bergström A, Lilja G, Pershagen G, Wickman M. Fish consumption during the first year of life and development of allergic diseases during childhood. Allergy 2006;61:1009-15.

34. Johansson I, Hallmans G, Wikman A, Biessy C, Riboli E, Kaaks R. Validation and calibration of food-frequency questionnaire measurements in the Northern Sweden Health and Disease cohort. Public Health Nutr 2002;5:487-96.

35. Brekke HK, Jansson PA, Månsson JE, Lenner RA. Lifestyle changes can be achieved through counseling and follow-up in first-degree relatives of patients with type 2 diabetes. J Am Diet Assoc 2003;103:835-43.

36. Conway JM, Ingwersen LA, Vinyard BT, Moshfegh AJ. Effectiveness of the US Department of Agriculture 5-step multiple-pass method in assessing food intake in obese and nonobese women. Am J Clin Nutr 2003;77:1171-8.

37. Lepage G, Roy CC. Improved recovery of fatty acid through direct transesterification without prior extraction or purification. J Lipid Res 1984;25:1391-6.

38. Hesselmar B, Sjöberg F, Saalman R, Aberg N, Adlerberth I, Wold AE. Pacifier cleaning practices and risk of allergy development. Pediatrics 2013;131:e1829-37.

39. Williams HC. Diagnostic criteria for atopic dermatitis. Lancet 1996;348:1391-2.

40. Bylesjö B, Rantalainen M, Cloarec O, Nicholson JK, Holmes E, Trygg J. OPLS Discriminant Analysis, combining the strengths of PLS-DA and SIMCA classification. J Chemometr 2007;20:341-51.

41. Trygg J, Wold S. Orthogonal projections to latent structures (O-PLS). J Chemometr 2002;16:119-28. 